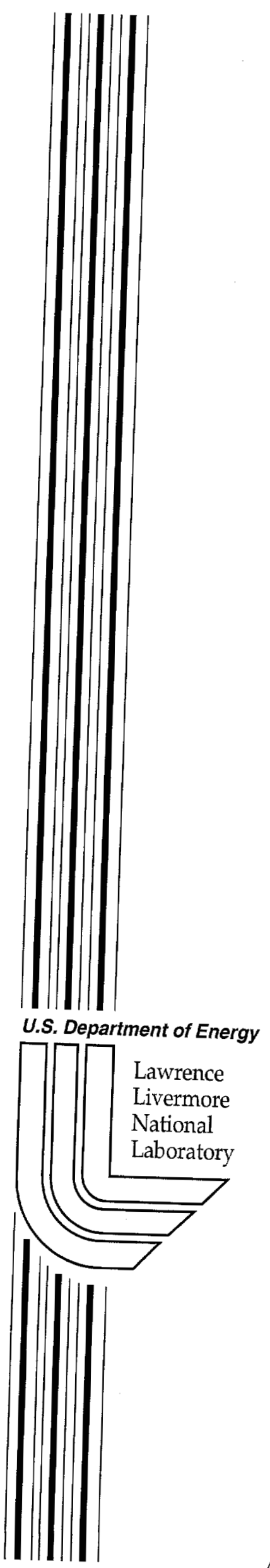

UCRL-ID-146792

\title{
Metal-Insulator Transition in Li and LiH - FINAL REPORT
}

M. Bastea, R.C. Cauble

January 15, 2002 


\section{DISCLAIMER}

This document was prepared as an account of work sponsored by an agency of the United States Government. Neither the United States Government nor the University of California nor any of their employees, makes any warranty, express or implied, or assumes any legal liability or responsibility for the accuracy, completeness, or usefulness of any information, apparatus, product, or process disclosed, or represents that its use would not infringe privately owned rights. Reference herein to any specific commercial product, process, or service by trade name, trademark, manufacturer, or otherwise, does not necessarily constitute or imply its endorsement, recommendation, or favoring by the United States Government or the University of California. The views and opinions of authors expressed herein do not necessarily state or reflect those of the United States Government or the University of California, and shall not be used for advertising or product endorsement purposes.

This work was performed under the auspices of the U. S. Department of Energy by the University of California, Lawrence Livermore National Laboratory under Contract No. W-7405-Eng-48.

This report has been reproduced directly from the best available copy.

Available electronically at http://www.doe.gov/bridge

Available for a processing fee to U.S. Department of Energy and its contractors in paper from

U.S. Department of Energy

Office of Scientific and Technical Information

P.O. Box 62

Oak Ridge, TN 37831-0062

Telephone: (865) 576-8401

Facsimile: (865) 576-5728

E-mail: reports@adonis.osti.gov

Available for the sale to the public from

U.S. Department of Commerce

National Technical Information Service

5285 Port Royal Road

Springfield, VA 22161

Telephone: (800) 553-6847

Facsimile: (703) 605-6900

E-mail: orders@ntis.fedworld.gov

Online ordering: http:/www.ntis.gov/ordering.htm

OR

Lawrence Livermore National Laboratory

Technical Information Department's Digital Library

http://www.llnl.gov/tid/Library.html 


\title{
Metal-Insulator Transition in Li and LiH - FINAL REPORT
}

\author{
Marina Bastea, Robert C. Cauble \\ Lawrence Livermore National Laboratory, P. O. Box 808, Livermore, CA 94550
}

The main goals of this project were the search for a predicted nonmetallic high-pressure phase of $\mathrm{Li}$ and finding the metallization conditions for LiH. It has been predicted by Neaton \& Ashcroft at Cornell [1] that the lithium atoms would pair at pressures around $100 \mathrm{GPa}$ and their valence electrons would become localized in the interstitial regions and therefore non-conducting. $\mathrm{LiH}$, an ionic compound, provides the unique opportunity to understand the effects of coupling two elements with opposite tendencies at extreme conditions and to study fundamental principles such as metallization and pairing.

We measured the electrical conductivity of liquid lithium at pressures up to 1.8 Mbar and 4-fold compression, achieved through shock reverberation experiments [2]. We found that the results were consistent with a departure of the electronic properties of lithium from the nearly free electron approximation at high pressures and with ionic pairing correlations in the Mbar regime. Given the expected small effect of the temperature on the conductivity at high densities, the apparent conductivity drop and the behavior of the ionic core at the highest pressures could be interpreted as a decrease of the overall volume available for the electrons. It may be interesting to see if the exclusionary effects mentioned above, that lead to a very non-1uniform distribution of the valence electrons, translate into the analog of classical depletion forces [3], enhancing the ionic pairing correlations in a mixture, e.g. LiH. Higher temperatures would ultimately destroy pairing correlations in the liquid. Estimates of the temperatures required should be possible, but need to rely on more detailed calculations, that could be tested against the experimental results of this study.

We have also done a preliminary measurement of the electrical conductivity of lithium 
hydride at $80 \mathrm{GPa}$. $\mathrm{LiH}$ appears to remain a good insulator at this high pressure. Due to difficulties in procuring the single-crystalline material the study of the high pressure properties of $\mathrm{LiH}$ could not be completed before the end of the project. Nevertheless we successfully conducted laser induced shock experiments on $\mathrm{LiH}$ in December 2001 at the Vulcan, U.K. laser facility and the data analysis is in progress. New experiments are in preparation at Omega for Feb. 2002 aimed at exploring metallization in a pressure regime up to $10 \mathrm{Mbar}$ on the Hugoniot of single-crystalline LiH.

More generally, during the course of this project we have developed the technique to measure the electrical conductivity of solid, reactive metals under dynamic compression. This newly acquired technical ability comsiderably strengthens the technical expertise of the shock physics group at LLNL and complements well the longstanding experience in electrical conductivity measurements on insulating fluids. The sample fabrication techniques we have developed for Lithium will allow us to study other reactive materials i.e. Praseodynium an f-electron transition metal and Phosphorus - which are very interesting due to their high pressure electronically induced volume collapse [4] and liquid-liquid phase transitions [5] respectively.

We have also developed and interfaced various computational tools in order to understand the experimental results. The transport properties of liquid metals are closely connected to their structural ones, which in turn can be understood in first approximation in the general context of liquid theory. Hydrodynamic codes that we adapted for experimental design in the study of the electrical conductivity of $\mathrm{Li}$ and $\mathrm{LiH}$ were enriched with new EOS models and successfully used as modeling and design tools for isentropic compression experiments. This small project successfully brought together expertise from several directories across the laboratory. We have worked closely with NIF-ICF group led by Gilbert Collins on the lasers experiments; C\&MS's Steve Letts on laser target coatings and Tom Felter for sample chemical analysis; Engineering (Larry Walkley) for the set-up of the reactive materials target fabrication laboratory.

Building on the knowledge and technical expertise we developed for this LDRD project, 
we have been able to undertake new challenges and plan future experiments related to the programatic goals of the laboratory, such as the NIF-first quarter experimental campaign. We are also actively engaged in sustained experimental efforts at the Sandia Z-pinch facility and Omega/Vulcan/Janus lasers aimed at understanding the high pressure physics fundamentals and elucidating the roles of time scales and size effects in shock experiments. The test system chosen is $\mathrm{LiH} / \mathrm{D}$ - a material with large uncertainties in the high pressure phase diagram and relevant for stockpile stewardship. 


\section{REFERENCES}

[1] J.B. Neaton, N.W. Ashcroft, Nature 400, 141 (1999).

[2] M. Bastea, S. Bastea, submitted to PRB.

[3] V. Vlachy, Langmuir 12, 2881 (1996).

[4] A. C. McMahan et. al., J. Comp.-Aided Mat. Design 5, 131(1998).

[5] Y. Katayama et. al., Nature 403, 170 (2000). 